\title{
Long-Range Scenario Construction for Technology Assessment
}

\author{
KAN CHEN, KENAN JARBOE, and JANET WOLFE
}

\begin{abstract}
Long-range scenario construction is an integral part of a technology assessment. Alternative future scenarios provide the socioeconomic context in which technological systcms can be forccast and assessed. Therefore, scenarios must be constructed in order to meet the information needs of all other portions of the study. One scenario construction approach, designed to meet this need, consists of the following elements: emphasis on range and consistency, specifically with respect to the technology assessed, combination of judgment and discipline, gradual divergence, and top-down variable disaggregation. As illustrated in an application to aviation communications technology assessment, this approach provides relevant information to the other portions of the study. Thus the scenarios provide the backdrop upon which the remainder of the study rests.
\end{abstract}

\section{Role of Scenarios}

Long passages of time are required for new technologies to diffuse, for large engineering systems to go through their life cycles, and for the indirect but potentially significant impacts of technology on society to manifest themselves. Therefore, the time horizon of comprehensive technology assessment studies, which purport to anticipate societal impacts of technology, often extends 25 to 50 years. Both the development of a specific technological application and its impacts depend on the societal context in which the technology operates. Long-range scenarios provide the context for an entire technology assessment study, embedding the other parts of the study within them.

The embedded nature of a technology assessment is described in Figure 1. The specific application of a technology (Box 4) is a subset of the general technological area (Box 2). Specific applications (Box 4) may have an impact on specific social sectors (Box 5), while the general technology may have general social impacts (Box 3), of which the specific sector impacts (Box 5) are a subset. Policy options (Box 6) considered in a particular technology assessment study are usually restricted to one or a few agencies or organizations of finite jurisdiction. As such, these policy options may affect both the specific applications (Box 4) and specific sector impacts (Box 5), but are unlikely to affect either the general technological area (Box 2) or the general social impacts (Box 3). All of the boxes are contained in the alternative future states of society (Box 1), which provides the broad societal context, but would not be influenced very much by the policy options or the technology and its societal impacts.

KAN CHEN, KENAN JARBOE, and JANET WOLFE are with the University of Michigan's Program in Technolugy Assessment at Ann Arbor, Michigan. 


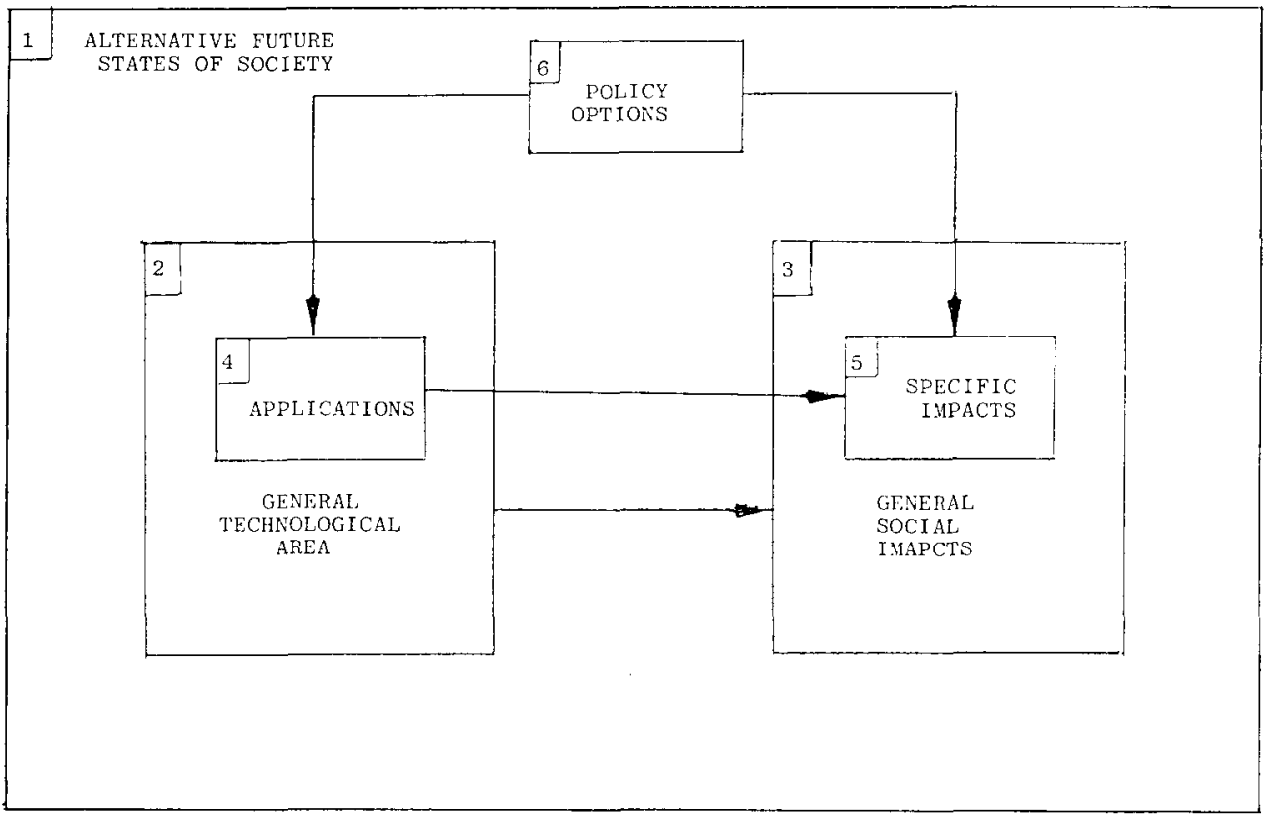

Fig. 1. Conceptual framework of a technology forecast and assessment study.

On the other hand, as the context for the rest of the study, the scenarios must serve the needs of the other portions of the study. Specifically, the scenarios must provide data, both quantitative and qualitative, for the technology forecasts (Boxes 2 and 4), provide the alternative contexts for the assessment of impacts (Boxes 3 and 5), and provide the context for the generation and analysis of policy options (Box 6). Thus our approach to scenario construction is guided by the needs of the entire technology assessment study.

\section{Scenario Construction}

Because no one can predict the future, especially the long-range future, with certainty, a set of alternative futures should be used. Although many future scenarios exist in the literature, the technology assessor often finds the existing scenarios unusable. In most cases the available scenarios are either too broad and qualitative to be relevant to future changes in the particular technology to be assessed, or too specific and quantitative to reflect a wide range of possible changes in social attitudes and institutions. Thus, few of the existing scenarios are able to both examine the innovation and diffusion process for a specific technology and, at the same time, describe the societal context in which the technolngy is to be assessed. These considerations lead to a basic approach to scenario construction for technology assessment that contains the following set of five attributes:

\section{Emphasis on Range and Consistency}

The set of scenarios should strive to cover a wide range of plausible futures, especially with respect to the general technological area and the specific application under study. Internal consistency within each scenario is necessary for credibility.

Significant factors affecting the technology to be assessed, both its capabilities and 
needs, must be included in the scenarios. This is crucial if the scenarios are meant to be part of a technology assessment study. Other factors that may be significant for society at large but not for the societal sector under study may be omitted.

\section{Combination of Judgment and Discipline}

The futures literature usually divides scenario construction into speculativequalitative descriptions and rigorous-quantitative modeling. The former suffers from a lack of discipline in imagination, while the latter precludes insightful judgment on the possible direction of basic societal transformation in the long run. In this approach, quantitative models based on empirical data are used for near-term forecasts, which provide a point of departure for longer-term forecasts on the basis of intuitive judgment as to what is plausible within the range of scenarios. Intuitive judgment is also important in analyzing the qualitative aspects of a scenario. Specifically, our approach uses a combination of intuitive judgment on macroattitudinal and institutional changes with rigorous, quantitative analysis on the micro variables relevant to the other parts of the study.

\section{Gradual Divergence}

Basic social forces, values, and institutions take considerable time to change. The range of scenarios is assumed to remain fairly small in the near term and to diverge gradually over the long term. The contrasts among scenarios increases over time, but all of them begin at a common point of departure in the present.

\section{Top-Down Approach}

The scenario construction starts with a set of themes that have different socioeconomic trends at the aggregate level. Each trend is then disaggregated to provide the required qualitative and quantitative descriptions at the micro level. Thus the basic approach involves the disaggregation of holistic scenarios into specific variables to meet the needs of other tasks within the technology assessment study.

Besides specifying the scenario dimensions and variables to be used, one must also clarify the time element of the scenarios. Scenarios are usually written in terms of static "snapshots," cross-sectional descriptions of the state of society at specific points in time (e.g., the levels of the scenario variables in the year $X$ ) and in terms of trajectories of dynamic trends over time (e.g., the rate of change of a scenario variable between year $X_{1}$ and year $X_{2}$ ). Both static snapshots and dynamic trends are needed to make up a complete and understandable "future history."

The number of snapshots to be developed (e.g., at 1980, 2000, and 2020) must be decided upon early, as it depends upon the information needs of the entire study and influences the number of scenario variables that may be analyzed within time and resource constraints of the study.

The development of the list of scenario dimensions and variables and the decision as to the number of snapshots to be constructed will be guided by three considerations:

1. The specific technical requirements of the study.

2. The internal needs of a scenario for sufficient clarification and explication.

3 . The resources and time allocated to task of scenario construction.

This basic approach has been applied to the construction of long-range scenarios of American society for the assessment of aviation communications technology to the year 
2020. A set of three alternative future scenarios was developed under the three themes of Balanced Growth, Rapid Growth, and Stagflation.

As shown in Figure 2, the study takes the top-down approach. Each theme begins with an internally consistent set of socioeconomic trends in terms of national attitudes, economy, and demographics. These trends, diverging from one another with the passage of time, are then elaborated in terms of the regulatory climate and national aviation activities, the latter being affected by the former via the deregulation (or reregulation) implemented by the Civil Aeronautics Board (CAB). To be relevant to aviation communications technology forecasting, the regulatory climate is translated into innovation and diffusion lags of different types of technological systems-general communications, and air-to-ground aviation communications. The national aviation activities are disaggregated into en route and hub level activities. These disaggregations are needed for other tasks within the technology assessment study, viz., the task of conditioned technology forecasting and the task of conceptual design of future aviation communication systems whose impacts are to be assessed.

Snapshots were developed for the years $1990,2000,2010$, and 2020 , along with descriptions of trends throughout the 1978-2020 time period.

\section{Three Scenarios}

Following the top-down approach, three divergent scenarios emerged. The three scenarios are briefly summarized in three contrasting narratives and are compared side by side in Table 1. Detailed descriptions of the scenarios are available elsewhere [1].

The Balanced Growth (Theme $X$ ) scenario takes as its starting point the Federal Aviation Administration's Baseline scenario. The dominant themes of "Balanced Growth" are the gradual transformation of the United States from an industrial society to

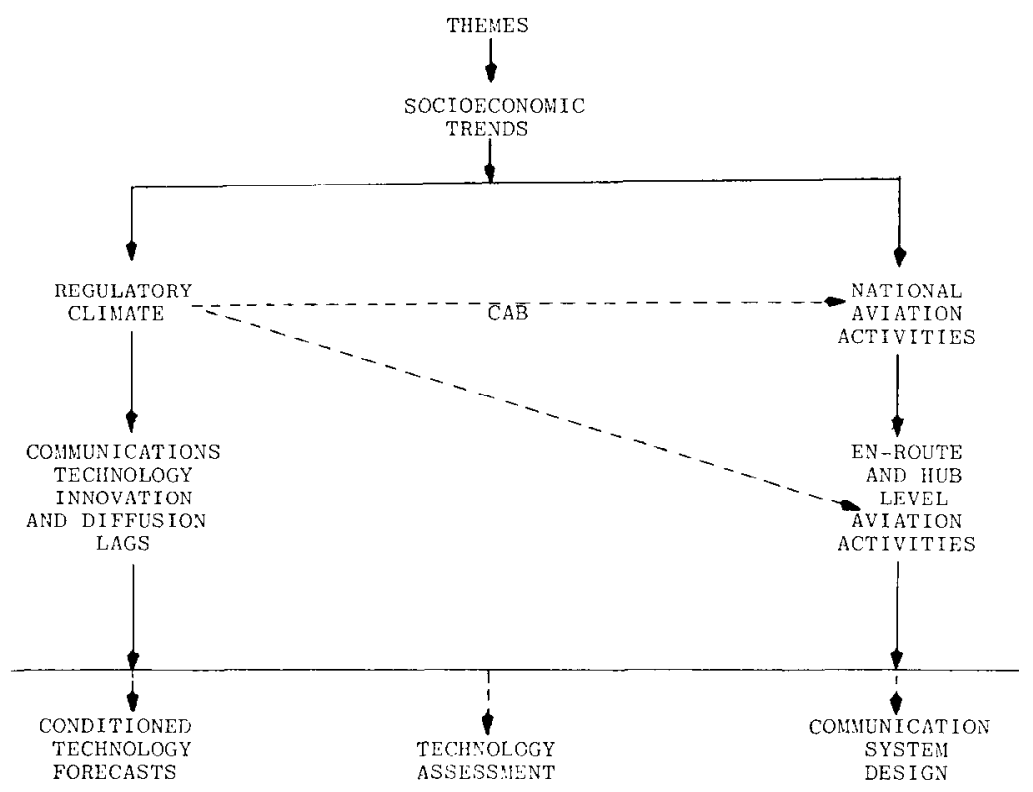

Fig. 2. A top-down approach to scenario construction. 
TABLE 1

Comparative Summary of the Three Scenarios

\begin{tabular}{|c|c|c|c|}
\hline & $\begin{array}{c}\text { Theme } X \text { : } \\
\text { balanced } \\
\text { growth }\end{array}$ & $\begin{array}{l}\text { Theme } Y \text { : } \\
\text { rapid } \\
\text { growth }\end{array}$ & $\begin{array}{l}\text { Theme } Z \text { : } \\
\text { stagflation }\end{array}$ \\
\hline Society and technology & $\begin{array}{l}\text { Social control of } \\
\text { technology }\end{array}$ & $\begin{array}{l}\text { Technological } \\
\text { dominance }\end{array}$ & $\begin{array}{l}\text { Antitechnology } \\
\text { backlash }\end{array}$ \\
\hline $\begin{array}{l}\text { Societal characteristics } \\
\text { by } 2000\end{array}$ & $\begin{array}{l}\text { Mature, stable infor- } \\
\text { mation society }\end{array}$ & $\begin{array}{l}\text { Continually expanding } \\
\text { information society }\end{array}$ & $\begin{array}{l}\text { Decaying, industrial } \\
\text { society }\end{array}$ \\
\hline $\begin{array}{l}\text { Population by } \\
2000 \text { (millions) }\end{array}$ & 294 & 362 & 281 \\
\hline Population distribution & $\begin{array}{l}\text { Decentralized to } \\
\text { medium and small } \\
\text { cities; balanced regional } \\
\text { distribution }\end{array}$ & $\begin{array}{l}\text { Megalopolises along } \\
\text { coasts, and Sun Belt }\end{array}$ & $\begin{array}{l}\text { Congested met- } \\
\text { ropolises; high growth } \\
\text { in Sun Belt }\end{array}$ \\
\hline Growth of GNP & Moderate $(3 \%)$ & High $(4.5 \%)$ & Low $(1.5 \%)$ \\
\hline Inflation & Moderate $(4 \%)$ & Low $(2 \%)$ & High $(8 \%)$ \\
\hline Productivity & Moderate & High & Low \\
\hline Regulation & Moderate regulation & Deregulation & Reregulation \\
\hline $\begin{array}{l}\text { Communications } \\
\text { technology innovation } \\
\text { lag (years) }\end{array}$ & 4.8 & 3 & 5.7 \\
\hline $\begin{array}{l}\text { Total aircraft operations } \\
\text { by } 2020 \text { (millions) }\end{array}$ & 161 & 250 & 90 \\
\hline
\end{tabular}

an information society with controlled development of technology. The balancing of economic and technological growth with social and environmental needs results in a modest rate of economic growth, carrying forward the general rate of economic growth forecasted for the years between 1979 and 1990 in the FAAs Baseline scenario. Family planning goes hand in hand with social and environmental planning, resulting in population increases that gradually approach zero population growth (ZPG) and a redistribution of population to smaller towns, cities, and rehabilitated inner cities. The various social goals are achieved by a mixture of government regulation and economic competition. Technological innovation is not rapid, but the selection and adoption of new technology by government agencies proceeds rationally, smoothly, and speedily. Aviation activity grows at a moderate rate with the major change coming in the growth of commuters and a shift in traffic density away from currently congested air corridors.

The major theme of the Rapid Growth scenario (Theme $Y$ ) is the transformation of the United States to an information society by way of technological determinism. Technological development is the driving force behind the societal transition. Rapid technological development leads to rapid economic growth. This rapid economic growth is a continuation of the growth rate used for the years 1979-1990 in the FAAs High Prosperity scenario, which serves as the starting point for the Rapid Growth scenario. Technological optimism and increasing affluence result in an increase in the fertility rate and continued population growth. Megalopolises expand as continued population growth 
and steady real prices of energy contribute to urban sprawl. Government intervention in private decision making is minimal, except in the antitrust area, where government policies and actions assure maximum competition and efficiency. In such a regulatory climate, new technologies proliferate and innovation lags become minimal. Because of the burden of choice, however, technology diffusion in government-owned systems is not so short as in the Balanced Growth scenario (Theme $X$ ). While aviation activities, especially general aviation, increase with the economic and technological growth, low-density urban sprawl and the development of competing modes of travel result in a relative decline in air commuter activity and a concentration of air carriers in high-density routes.

The Stagflation scenario (Theme $Z$ ) is prolonged economic stagnation combined with excessive inflation. This scenario is built upon the motif of acute tension within society combined with an antitechnology backlash. The result is that the United States becomes a decaying industrial country rather than an information society. Tension among groups over entitlements, a growing antitechnology mood within the body politic, and rising energy prices lead to stagflated-economic conditions. The economic conditions of the FAAs Slow Growth scenario, which is used by the Stagflation scenario as a starting point, are therefore carried forward past the year 1990 to the year 2020. Stagnant economic conditions and high levels of frustration, anxiety, and tension result in the postponement of childbearing, which slows population growth. Rising energy prices accelerate the gentrification of the inner city, displacing the poor to outer rings and suburbs abandoned by the middle class. Angry and frustrated interest groups force the government to intervene in many private decisions and to step up regulatory actions. Technological innovation and frustration lags lengthen in the uncertain regulatory climate. Growth in aviation activities slows with the declining economic growth rate, and general aviation activities decline. Basic air traffic flow patterns remain much the same as they are at present.

\section{Evolution of the Themes}

As mentioned earlier, the three scenarios are built around three different themes. Several considerations went into the choice of these three major themes. For the purpose of this study, the scenarios must be relevant to 1) technology, 2) communication, and 3) aviation. The review of the futures literature was thus guided by the criterion of relevancy to these areas.

The consideration of technology focused attention on the technology's place in society. One school of thought holds that, in the partnership between society and technology, society is decidedly the junior partner. According to this theory of technological determinism, technology is an independent driving force that will progress according to its own pace, pulling society along behind it. This school of thought has two major branches. The optimistic branch, as characterized by Kahn [15], states that technological development is inherently good and that society should eagerly follow wherever technology leads. The optimistic view of technological determinism forms the basis for the Rapid Growth theme.

The second branch of technological determinism is a pessimistic view, as described by Ellul [6]. This view holds that while technology may be the driving force, the costs to society of following where technology leads outweigh the benefits. Yet society is unwilling to unable to exercise control over technology, which takes on a life of its own, like the sorcerer's broom. This pessimistic view forms one of the cores around which the Stagflation theme is built.

The other school of thought on the relationship between technology and society is 
that society can and should exercise control over technology. This view of society and technology as equal partners is the basis of much of the technology assessment movement. Numerous authors, such as Michael [18], Harmon [13], and Henderson [14], have described this view in great detail. The relationship between technology and society in the Balanced Growth theme is one of controlled development of technology within the body politic.

The consideration of communications focuses attention on the transition of the United States from an industrial society to an information society. This transition has been pointed out by Porat [19], who observed that the percentage of employee compensation for information-related workers was equal to $53.52 \%$ of the national total in 1967 . According to Porat, American workers in information occupations now make up the largest single sector, above the agricultural, industrial, and service sectors. The transition of the United States to an information society both drives and is driven by trends in communications. That the United States is shifting to an information society is assumed in all three scenarios. Where differences arise among the scenarios, they are a result of different assumptions as to speed and difficulty in this transition. For the sake of this study, it was postulated that the shift to an information society will continue vigorously, although along different paths, in both the Balanced Growth $(X)$ and Rapid Growth $(Y)$ themes. In the Stagflation $(Z)$ theme, it was postulated that the shift to an information society meets with serious difficulties and that the United States becomes a decaying industrial nation.

The consideration of aviation led to building three scenarios (to A.D. 1990) used in the FAA aviation forecasts [9] and the three scenarios (to A.D. 2000) used in the FAA microcomputer technology forecast and assessment [21]. These two sets of scenarios have influenced the selection and elaboration of the three themes in this report. In fact, the basic description of the shorter-term futures (to A.D. 1990) has been essentially the same as in the FAA forecasts.

\section{Scenario Variables}

Following the top-down approach shown in Figure 2, the themes are developed in terms of descriptive variables. Within each theme, the descriptive variables for the socioeconomic trend include the following: attitudes, demography, economies, regulation, and aviation. These five dimensions were chosen as they are all required by the next level of disaggregation in the two directions shown in Figure 2.

\section{ATTITUDINAL VARIABLES}

Attitudinal variables are qualitative descriptors of dominant societal characteristics and societal attitudes toward society-technology relationships. The description of the attitudinal variables in the three scenarios was determined by two of the three considerations outlined earlier specifically, technology and communications. Thus the attitudinal variables, to a large extent determine the makeup of the scenarios and, therefore, drive the other scenario variables. The Balanced Growth scenario describes a mature information society with controlled development of technology. The Rapid Growth scenario paints the picture of a continually expanding information society. driven by technological dominance. The Stagflation scenario shows a decaying industrial society plagued by acute conflict and a prevalent antitechnology mood.

\section{DEMOGRAPHIC VARIABLES}

In the category of demographic variables we determined that three disaggregated 
variables were needed: total population, labor force, and population distribution patterns The total population and size of the labor force were needed as inputs into the economic section. Population distribution patterns were needed in determining aviation demands.

The population projections used in all three scenarios were developed by the U.S. Bureau of the Census [20]. The Balanced Growth scenario uses the Bureau's Series II projection, which assumes a fertility rate set at the replacement level of 2.1. The Rapid Growth scenario uses the Bureau's Series I projection with the fertility rate set above the replacement level. Although the fertility rate of 2.7 in Series I seems a bit high, no other projection of United States population figures are found that assume a fertility rate between 2.1 and 2.7. The Stagflation scenario uses the population projections of the Census Bureau's Series II-L. Series II-L assumes a fertility rate of 2.1 and the higher median age of childbearing of 28 .

Labor force participation rates by sex and age cohort were determined judgmentally based both on past trends and on the attitudinal economic descriptions of cach sccnario. Past trends, as described by Bednarzik and Klein [2], show that labor force participation rates for men have been declining somewhat while participation rates for women have been climbing, even for women in the major childbearing years. In the Balanced Growth scenario, it was assumed that this convergence of male and female participation rates would continue until the rates become equal around the year 2000 .

The Rapid Growth scenario also assumes a continuation of the trend of rising participation rates for women and falling rates for men, but does not assume complete convergence of the participation rate. In the Stagflation scenario, labor force participation rates are only slightly different from current conditions.

With regard to population distribution, the scenarios are principally a function of energy prices. In the Balanced Growth scenario, by the year 2020 current urbanized conditions change with a dispersion of the population to smaller cities accompanied by the gentrification of many inner city areas. In the Rapid Growth scenario, urban sprawl is driven onward as few negative forces act to retard population spread. In the Stagflation scenario, population tends to cluster in large metropolitan areas, rather than spread into local and regional nodes as in the Balanced Growth scenario.

\section{ECONOMIC VARIABLES}

The key economic variables needed in this study were determined to be the gross national product (GNP), the unemployment rate, size of civilian employment, consumer price index (CPI), disposable personal income, and energy prices. All of these variables serve as inputs in calculating key aviation variables. Business productivity was used as an internal variable within the economic section for use as a consistency measure.

The economic projections presented in the scenario descriptions are divided into the shorter-term future (between now and 1990) and the longer-term future (between 1990 and 2020). The shorter-term economic projections were taken directly from the FAA [9] forecasts. The economic projections to the year 1990 in the FAA forecasts are based on simulations of the Wharton Long-Term Industry and Economic Forecasting Model.

The longer-term economic projections beyond 1990 were obtained through a modified form of extrapolation. The modifications were based on the attitudinal and demographic descriptions of the three themes. First, GNP was extrapolated from the trends described in the FAA scenarios. This resulted in preliminary levels of GNP and the GNP growth rate for each scenario in 2000, 2010, 2020. Next the approximate size of the labor force for each scenario in 1990,2000, 2010 and 2020 was calculated based on judgments concerning labor force participation rates by sex and age cohort. Unemploy- 
ment was held at $4 \%$, the generally accepted "full employment" level, in the Balanced Growth and Rapid Growth scenarios. Unemployment was tentatively set at $7 \%$ in the Stagflation scenario, reflecting the unemployment rate in the corresponding shorter-term FAA scenario. Given the approximate level of GNP unemployment, and the size of the labor force, the implied business productivity was calculated.

With these assumptions, the levels of real GNP, business productivity, and for the Stagflation scenario, unemployment, were modified judgmentally until all levels and growth rates were deemed consistent with both the attitudinal descriptions and the 1990 data from shorter-term forecasts. Price indices, for both CPI and energy, were developed judgmentally, to be consistent with the attitudinal description and the shorter-term forecasts.

\section{REGULATORY AND TECHNOLOGY DIFFUSION VARIABLES}

The regulatory descriptions in the scenarios help to determine technological diffusion rates and aviation variables. As inputs into the aviation sector, the civil aviation regulation descriptions provide the bases upon which intuitive judgments are made. The diffusion rates, derived partly from the regulatory descriptions, will be used later in the study to condition the technology forecasts of aviation communications as functions of alternative future scenarios.

Forecasts of the regulatory climate are based on a review of recent literature relating to legislative and regulatory proposals in the communications area, antitrust regulation of the computer and communications industries, frequency spectrum allocations, airline fare and route regulation, and on interviews with active and knowledgeable persons in both the public and private sectors. The direction and speed of change in the regulatory climate are related to the socioeconomic trends of the scenarios. Specifically, the Balanced Growth scenario tends toward moderate regulation; the Rapid Growth scenarios tends toward substantial deregulation; the Stagflation scenario includes substantial reregulation.

The regulatory climate was then converted to a quantitative description of technology innovation and diffusion lags in the electronics, computer, and communications industries, with considerations given to implications for technological changes in aviation communications. The model of technological changes used in this study consists of an innovation process and a diffusion process. The innovation process is further divisible into two stages: from ideation to prototype testing, and from prototype testing to market introduction. All of these stages and processes are assumed to take place in tandem. To determine the specific time lags in each scenario, data on current and past innovations and diffusion lags $[7,11]$ were modified judgmentally, according to the socioeconomic and regulatory descriptions for each scenario. Thus the time lag from ideation to market saturation in the Stagflation scenario is greater than in the Balanced Growth scenario. The Rapid Growth scenario contains the shortest lag of all three scenarios.

\section{AVIATION VARIABLES}

The purpose of this particular technology assessment study is to anticipate the impacts of future aviation communications systems. In order to postulate these future systems, two descriptions are needed: 1) a description of the available technology (conditioned technology forecast) and 2) a description of the system requirements, as determined by the number of aircraft operating at any one time in the system. Thus the key aviation variable is the level of en route and hub aviation activities, which is projected partly on the basis of a forecast of national aviation activities. 
The forecasts of national aviation activities are based on modifications of the current FAA approach and associated models. Aviation activities are forecast for each of three sectors: 1) air carriers, 2) general aviation, including air commuters, and 3) military aircraft. The FAA forecasts for all sectors through the year 1990 are taken without modification of current FAA models $[9,10,14]$. Those forecasts for military aircraft are obtained from trends of changes in relative shares (proportion of each sector to total national aviation activity) with judgmental modification.

The forecasts of en route and hub level aviation activities made use of recent and current studies conducted by MITRE Corporation and the Department of Transportation (DOT) Transportation Systems Center $[3,4,5]$. The current relationship is first obtained between the national level and the typical en route and hub level aviation activities. The proportions are then changed over time, the direction and amount of change being judged on the basis of the socioeconomic trend of each scenario. The proportions are modified specifically to take account of the relative concentration of aviation activity along major routes and in major hubs by scenario, because of variations in 1) the population distribution and 2) the regulation of civil aviation.

\section{Application of Scenarios}

The three scenarios summarized earlicr and in Table 1 have been used to provide relevant information to other tasks within the aviation communications technology assessment study. One specific application is to condition the technology forecasts on the scenarios. The other application is to provide the relevant contexts for specific communications system design. These two applications will be illustrated below.

There are two basic notions underlying the methodology for conditioned technological forecasting. The first notion is that technological changes in a particular field will be orderly. The second notion is that the rate of such orderly technological changes will be dependent on scenarios. These two notions lead to a model of technological development with an elastic time scale, which may be represented quantitatively by the following "telescoping equation" [21]:

$c_{j}(t)=c_{i}\left[a_{i j}(t-1980)+1980\right] \quad$ for $t \geqslant 1980$

where

$c=$ technological characteristic (e.g., computer speed)

$t=$ time in various years (e.g., 1995)

$i=$ index of the scenarios for which a technological forecast is available

$j=$ index of scenarios for which a different technological forecast is to be derived

$a_{i j}=$ accelerations factor between the $i^{\text {th }}$ and the $a^{\text {th }}$ scenarios.

Now the acceleration factor $a_{i j}$ may be derived from the difference in technology innovation lags between scenarios, such as given in Table 1. Suppose we already have the technological forecast for the $i^{\text {th }}$ scenario. Let $T_{i}$ be the innovation time lag in the $i^{\text {th }}$ scenario, and $T_{j}$ be that in the $j^{\text {th }}$ scenario. An industry or a company usually begins to develop the next technological idea after the current idea has progressed to a certain stage toward or beyond market introduction. This notion is depicted by the time lines in Figure 3 . Thus, the next ideation takes place at the time $b T_{i}$ after the current ideation, where $b$ may be greater or less than unity but is approximately a constant. 

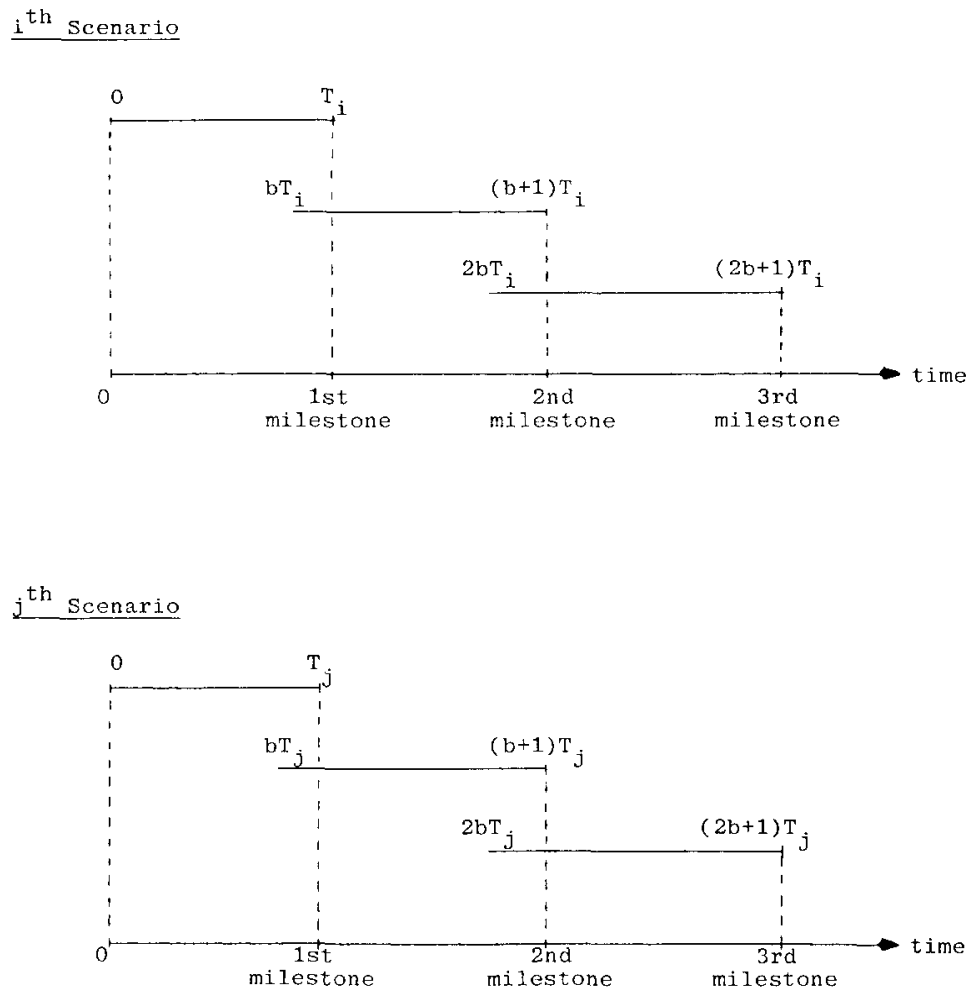

Fig. 3. Dynamics of the same technological development in two different scenarios.

It is evident from Figure 3 that the $n^{\text {th }}$ milestone of the same technological development is reached at different times in different scenarios. The time when the $n^{\text {th }}$ milestone is reached in the $i^{\text {th }}$ scenario is $[(n-1) b+1] T_{i}$ at the time for the same milestone is reached in the $j^{\text {th }}$ scenario is $\left.[(n-1)] b+1\right] T_{j}$. Thus the acceleration factor is

$$
a_{i j}=\frac{[(n-1) b+1] T_{i}}{[(n-1) b+1] T_{j}}=\frac{T_{i}}{T_{j}} .
$$

In other words, the acceleration factor $a_{i j}$ is simply the ratio between the innovation time lags of the two scenarios. Using the time lags for communications technology innovation lags in Table 1 and applying equation (2), we obtain the acceleration factors as follows:

\begin{tabular}{|c|c|}
\hline Scenarios & Acceleration Factors \\
\hline X: Balanced Growth & 1 (base) \\
\hline Y: Rapid Growth & $1.6(=4.8 / 3)$ \\
\hline Z: Stagflation & $0.842(=4.8 / 5.7)$ \\
\hline
\end{tabular}

Applying these acceleration factors to the results of technological forecasts of communications technology for the baseline case [16], we obtain, for example, the conditioned forecasts of the average number of wideband transponder channels per communications satellite as shown below and as portrayed in Figure 4. 


\begin{tabular}{lccc}
\hline \multirow{2}{*}{$\begin{array}{c}\text { Number of } \\
\text { wideband channels } \\
\text { per satellite }\end{array}$} & \multicolumn{3}{c}{$\begin{array}{c}\text { Scenarios } \\
\text { (year) }\end{array}$} \\
\cline { 2 - 4 } & $X$ & $Y$ & $Z$ \\
\hline 612 & 1980 & 1980 & 1980 \\
1310 & 1985 & 1983.1 & 1985.9 \\
2005 & 1990 & 1986.3 & 1991.9 \\
2725 & 1995 & 1989.4 & 1997.8 \\
3882 & 2000 & 1992.5 & 2003.8 \\
\hline
\end{tabular}

Similar conditioned forecasts have been obtained for all the relevant significant technologies in the aviation communications technology assessment study.

The second application of the scenarios in the same study is more conceptual than numerical. On the basis of the communications requirements implied by the three scenarios, such as the number of total aircraft operations given in Table 1, three different system configurations have been developed for aviation communications for the year 2020 [17]. The basic difference in the system configurations lies in the partitioning of the

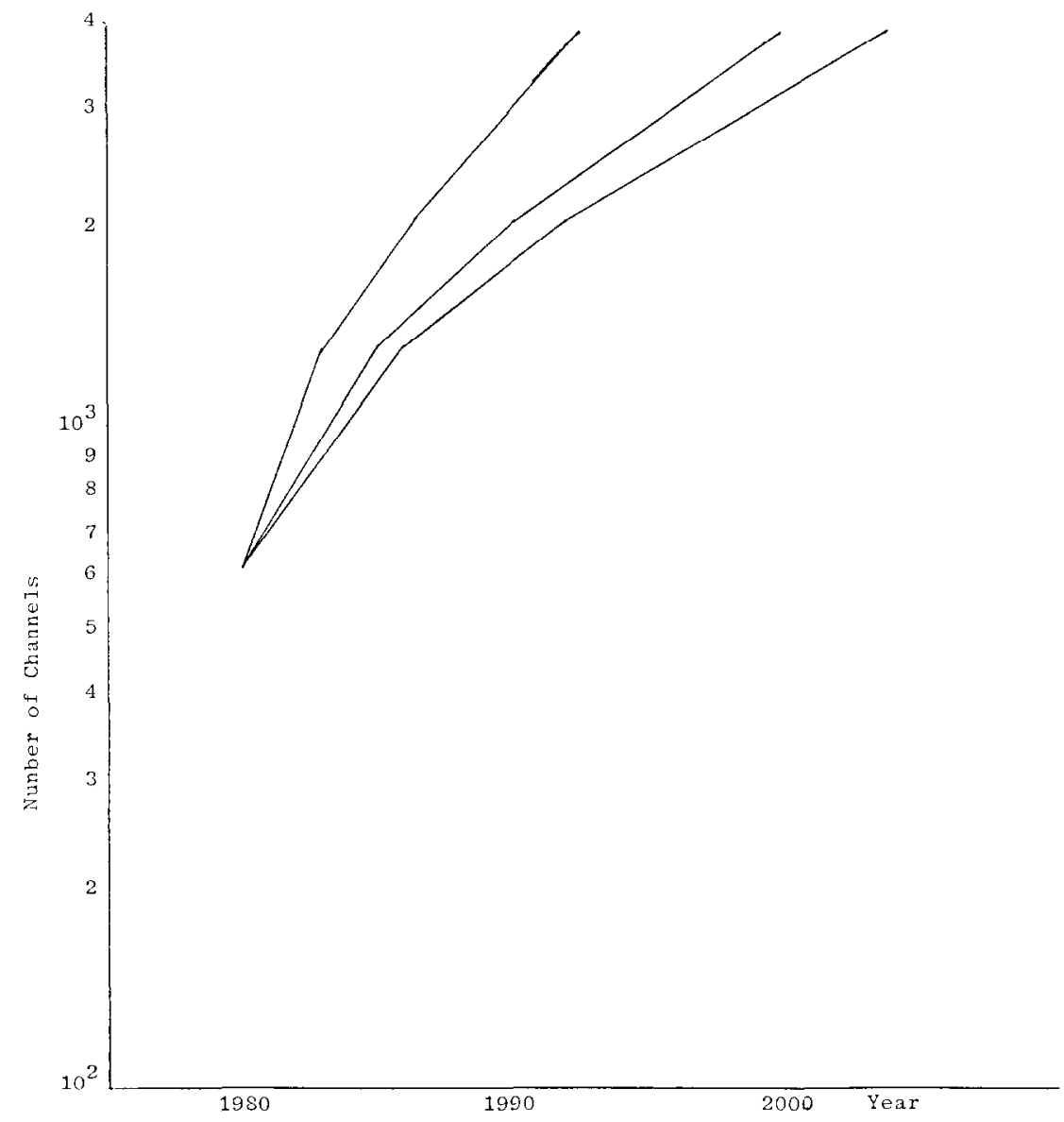

Fig. 4. Number of wideband channels per satellite: conditioned forecast. 
various air traffic control (ATC) systems between space and terrestrial orientation. In the Rapid Growth scenario $(Y)$, technology will be available to have all functions of the ATC system space-based, except for ground-to-ground communications, which will be a mix of space and terrestrial systems. In the Balanced Growth scenario $(X)$, several of the ATC functions will continue to be based terrestrially but will be aided by satellites to extend coverage and capacity. This satellite-aided concept would require less orbit space, fewer beams for communications satellites, and so on, and thus is less technologically advanced as compared to the fully space-oriented concept for scenario $Y$. Finally, in the Stagflation scenario $(Z)$, the terrestrial system as projected in the current FAA plans for the late 1990s is assumed to be very similar. These different communications system designs provide fundamentally different technological bases for impact assessments. In other words, both the future technology and its social context are conditioned by the scenarios in the technology assessment study.

\section{Conclusions}

No one can predict our societal future with certainty, especially over a long period of time. It does make sense, however, to consider a set of alternative futures that are plausible on the basis of what we know today and that can provide the socioeconomic context in which alternative technological system concepts can be compared and assessed analytically. The scenario construction technique outlined here is designed to provide a technology assessment study with the necessary socioeconomic context. It does so by focusing on the specific area of technology to be assessed. Such narrow focusing, however, may lead to a myopic view with the corresponding risk of missing vital but indirect developments. Fortunately, the technique also emphasizes constructing a range of scenarios based on differing themes. Following a top-down approach, these themes are disaggregated until the level of specificity needed is reached. Because social value and institutions change slowly over time, the disaggregated variables are described as gradually diverging over time. The use of both qualitative judgment and quantitative analysis, on the one hand, guards against the pitfall of leaving out unquantifiable but significant variables in the scenarios, and on the other hand, brings into play the rigor and discipline of quantitative methods.

It should be noted that the technique is not a once-through approach. The purpose of the scenario is to provide information to other portions of the study. It would be presumptuous to assume that, before we complete the study, we could know exactly all of the information that might be needed during the later portions of the study. Portions of the scenarios may well require refinement as the study progresses. The basic approach, however, as characterized by the five attributes, need not be changed.

\section{References}

1. Acumenics Research and Technology, Inc., Socioeconomic Impact Assessment, Communications Industry-Phase I and II Draft Report: Description and Documentation of the Current State-of-the-Art (1979).

2. Bednarzik, Robert W., and Klein, Deborah P., Labor Force Trends, Monthly Labor Review, U.S. Bureau of Labor Statistics (October 1977).

3. Cohen, Saul, Statistical Summary of the 1983 Los Angeles En Route Center Standard Traffic Model. MITRE Technical Report MTR-6676 (1974).

4. Cohen, Saul, and Maginnis, Frank, Statistical Summary of the 1982 Los Angeles Basin Standard Traffic Model, FAA-RD-73-87 (1973). 
5. Cohen, Saul, and Maginnis, Frank, Extrapolation Methodology Used in the Los Angeles Basin Standard Traffic Model, FAA-RD-73-86 (1973).

6. Ellul, Jaques, The Technological Society, Vintage, New York, 1976.

7. Ewell, Samuel, Statement on Behalf of Aeronautical Radio, Inc., Exploratory Hearings in the Domestic: Telecommunications Industry, by the Subcommittee on Communications of the Committee on Interstate and Foreign Commerce, United States House of Representatives, pp. 665-666 (September 29, 1976).

8. FAA, The Impact of Microcomputers on Aviation: A Technology Forecasting and Assessment Study (2 volumes), DOT FA76WAI609 (1977).

9. FAA, FAA Aviation Forecasts, Fiscal Years 1979-1990, FAA-A VP-78-11 (1978).

10. Gershkoff, Ira, and Hannon, Bernard, Macro Air Carrier Forecasting Model, FAA Aviation Forecasts, Fiscal Years 1978-1990. FAA-A VP-78-11 (1978).

11. Gellman Research Associates, Indicators of International Trends in Technological Innovation, National Science Foundation (NTIS), PB-263-738 (1976).

12. Harman, Willis W., An Incomplete Guide to the Future, San Francisco Book Co. (1976).

13. Henderson, Hazel, Creating Alternative Futures, Berkley Publishing, New York (1978).

14. Henry, Thomas F., Kruzic, Pamela, and Hartwill, Janice, General Aviation Forecasting Model, (mimeo.) FAA/A VP, (1978).

15. Kahn, Herman et al., The Next 200 Years, William Morrow, New York (1976).

16. Martino, Joseph P., "Satellite Communication Systems," report to Acumenics Research and Technology, Inc., (1979).

17. Meer, Ahmed, "Aviation Communications in 2020 A.D.," report to Acumenics Research and Technology, Inc. (1980).

18. Michael, Donald N., On Learning to Plan and Planning to Learn, Jossey-Bass, San Francisco, 1973.

19. Porat, Mare, Policy in an Information Society, Communications for Tomorrow, Glen O. Robinson (ed.), Aspen Institute for Humanistic Studies and Praeger Publishers (1978).

20. United States Bureau of the Census, Projections of the Population of the United States; 1975-2050, Current Population Reports, Series P-25, no. 601 (1975).

21. Wise, Kendall, D., Chen, Kan, and Yokely, Ronald E., Microcomputers: A Technology Forecast and Assessment to the Year 2000, John Wiley, New York (1980).

Received 16 February 1981; revised 10 June 1981 